\title{
Determining Relative-Importance of the Drivers of Employee Engagement, Enablement, and Empowerment Using Analytic Hierarchy Process for Developing Sustainable Employee Excellence in Manufacturing Environment in Indonesia
}

Iman Permana

\author{
Jann Hidajat Tjakraatmadja
}

Dwi Larso

\section{Agung Wicaksono}

\author{
School of Business and Management, Bandung Institute of Technology, Indonesia
}

Email: iman.permana@sbm-itb.ac.id

Doi:10.5901/mjss.2015.v6n3s2p600

Abstract

Having a high-performing business culture is a competitive advantage for businesses to thrive in today's business dynamics. Every employee, through her/his actions, can make the culture stronger or weaker. Previous studies revealed that how engaged, how enabled, and how empowered employees were in day-to-day work activities influenced their excellence at work. This paper discusses the results of a study aimed at determining the relative-importance of the drivers of employee engagement, enablement, and empowerment, based a framework proposed in a previous study. The framework incorporated constructs of engagement, enablement, and empowerment for building and sustaining employee excellence in manufacturing organizations in Indonesia. This study assessed the relative-importance by conducting pairwise comparisons and analytic hierarchy processes. Further confirmation was then done with a quadrant analysis of importance-vs-observance. The findings revealed that being confident of own future in the organization, supportive working environment, and superior's willingness to delegate are respectively the most important drivers for engaging, enabling and empowering employees. The results provide empirical basis for making decisions and taking action on the most important factors for influencing employee engagement, enablement, and empowerment, in an effort to understand how to pave the way for developing employee excellence.

Keywords: relative-importance; engagement; enablement; empowerment; analytic hierarchy processes

\section{Introduction}

As the global economy gathers pace, the marketplace becomes increasingly competitive. The pace of change is accelerated by technological developments, competitions, and consumers' demands. Hence, developing an organization that can adapt quickly to change is critical for sustainable success. More than anything, this kind of organization requires people as the key success factor. It is people who formulate strategies and execute those strategies. It is people who transform their organization to greatness. People, or employees, play important roles in the functioning of the organization. Toyota, one of the most successful companies in the world, regards its employees as its secret of success in their more-than-30-years tenure of excellence. Liker and Meier (2007) in their book 'Toyota Talent' disclosed that it is the knowledge and capability of people that distinguish Toyota from other organizations.

A study by Hay Group (2010) revealed that employees who are both highly engaged and enabled are $50 \%$ more likely to outperform expectations. It also reported that companies in the top quartile on both engagement and enablement achieved revenue growth 4.5 times greater than their industry peers who focused on engagement alone. Other studies, such as by Conger and Kanungo (1988), showed that employees' performance correlated with their capabilities of problem solving and decision making. These suggest that members of an organization must be engaged, enabled, and empowered to excel in it. Therefore, it is of utmost importance for organizations to understand what drives people to be engaged, to be enabled, and to be empowered. This is where the constructs of engagement, enablement, and empowerment come into play. Permana, Tjakraatmadja, Larso, and Wicaksono (2015) argued that these constructs are distinct and that, to be sustainable, employee excellence must come from the three constructs altogether. 


\subsection{Purpose}

This study was conducted with the research questions of "which drivers are important to be included in the constructs of employee engagement, enablement, and empowerment?" and "which of the drivers included in the constructs are the most important for predicting employee engagement, enablement, and empowerment?" Building on these research questions, the study proceeded with the research objective of seeking key drivers of employee engagement, enablement, and empowerment in search of important factors for developing employee excellence.

\section{Literature Review}

\subsection{Potential drivers of employee engagement, enablement, and empowerment}

A framework for developing sustainable employee excellence through the constructs of employee engagement, enablement, and empowerment was proposed by Permana et al. (2015). This framework was build based on significant literature study and confirmed with massive interviews with managers, foremen, superiors of the foremen, and subordinates of the foremen in several manufacturing companies in Indonesia. This framework defines employee engagement as 'the intensity of employees' emotional connection (i.e. attachment) that they feel for their organization, which influences them to exert greater discretionary effort (i.e. extra effort) committed to achieving their work goals,' with eleven potential drivers as shown in Tabel 1. These drivers are called 'potential' at this stage, which were then assessed in this study with further analysis to be the confirmed drivers.

Table 1. List of potential drivers of engagement

(Permana et al., 2015)

\begin{tabular}{|c|c|}
\hline Potential drivers & Definition \\
\hline $\mathrm{X}_{1}$, vision & The extent to which an employee is confident with her/his future in the organization. \\
\hline $\mathrm{X}_{2}$, passion & $\begin{array}{l}\text { The extent to which an employee is motivated to contribute to organizational success by willingly } \\
\text { applying discretionary efforts to accomplishing tasks important to achieving organizational goals. }\end{array}$ \\
\hline$X_{3}$, reward/ recognition & $\begin{array}{l}\text { How an employee perceives her/his reward for certain work outcome, that is the recognition she/he } \\
\text { receives from her/his superior for the performance she/he has contributed to her/his work. }\end{array}$ \\
\hline $\mathrm{X}_{4}$, job satisfaction & $\begin{array}{l}\text { Personal satisfaction resulting from individuals' contribution to the company's success, which represents } \\
\text { an alignment of maximum job satisfaction with maximum job contribution. }\end{array}$ \\
\hline $\begin{array}{l}\mathrm{X}_{5} \text {, alignment of value and } \\
\text { interest }\end{array}$ & $\begin{array}{l}\text { The extent to which an employee sees a mutuality of interest between her/his values and aspirations and } \\
\text { those of the organization. }\end{array}$ \\
\hline $\mathrm{X}_{6}$, work accomplishment & The extent to which the work itself gives an employee a feeling of personal accomplishment. \\
\hline $\begin{array}{l}\mathrm{X}_{7} \text {, opportunity for } \\
\text { personal growth }\end{array}$ & $\begin{array}{l}\text { The extent to which an employee believes that she/he has opportunities for growth and development in } \\
\text { the organization. }\end{array}$ \\
\hline $\mathrm{X}_{8}$, trust in leadership & $\begin{array}{l}\text { How an employee perceives that the values of the organization are evident in senior management's } \\
\text { actions. }\end{array}$ \\
\hline$X_{9}$, psychological capital & $\begin{array}{l}\text { Positive psychological state of development of an employee, which is characterized by having confidence } \\
\text { (self-efficacy) to take on and put in the necessary effort to succeed at challenging tasks, making a } \\
\text { positive attribution (optimism) about succeeding now and in the future, persevering toward goals, } \\
\text { redirecting paths to goals (hope) when necessary in order to succeed, and sustaining and bouncing back } \\
\text { (resilience) when beset by problems and adversity. }\end{array}$ \\
\hline$X_{10}$, person's fit with job & $\begin{array}{l}\text { The extent to which an employee is 'absorbed' in her/his work resulting in a sense of engrossment when } \\
\text { doing the work and how much 'energy' she/he draws from such work. }\end{array}$ \\
\hline $\begin{array}{l}X_{11} \text {, person's fit with } \\
\text { organization }\end{array}$ & $\begin{array}{l}\text { The extent to which an employee's views of the organization's direction are aligned with the direction } \\
\text { being taken by the organization and how much she/he 'identifies' herself/himself as part of the } \\
\text { organization. }\end{array}$ \\
\hline
\end{tabular}

The framework defines employee enablement as 'the extend to which employees feel they are provided with what they need to do their jobs well and are provided with an environment in which they feel comfortable to perform to the best they can be.' This construct has seven potential drivers as shown in Table 2. 
Table 2. List of potential drivers of enablement

(Permana et al., 2015)

\begin{tabular}{|c|c|}
\hline Potential drivers & Definition \\
\hline $\begin{array}{l}Y_{1} \text {, adequacy of work equipment } \\
\text { and supplies }\end{array}$ & $\begin{array}{l}\text { The extent to which an employee perceives how adequately the organization provides well- } \\
\text { functioning equipment and the necessary supplies of work materials, which play significant } \\
\text { roles in how well the employee gets the job done. }\end{array}$ \\
\hline & The extent to which an employee is aware of and understands the direction that the \\
\hline $\mathrm{Y}_{2}$, clear direction & $\begin{array}{l}\text { organization provides and communicates to employees to enable them to carry out the tasks in } \\
\text { their job. }\end{array}$ \\
\hline$Y_{3}$, effective work processes & $\begin{array}{l}\text { The extent to which an employee perceives that the organization provides effective work } \\
\text { processes, which contribute to her/his ability to get jobs done. }\end{array}$ \\
\hline $\begin{array}{l}\mathrm{Y}_{4} \text {, supportive working } \\
\text { environment }\end{array}$ & $\begin{array}{l}\text { How an employee perceives how collaborative is the organization's working environment with } \\
\text { regards to motivating people and reducing the cost of working together in such an extent that it } \\
\text { allures enough people to handle the workload. }\end{array}$ \\
\hline$Y_{5}$, job design & $\begin{array}{l}\text { The extent to which an employee is aware of and understand that the organization attempts to } \\
\text { give the right position to the right people (i.e. how the organization designs jobs), which will } \\
\text { expectedly allow people to carry out their tasks optimally. }\end{array}$ \\
\hline$Y_{6}$, infrastructure for data sharing & $\begin{array}{l}\text { The extent to which an employee is aware of and understands that the organization provides } \\
\text { infrastructure for sharing data that help employees to understand the context of their work and } \\
\text { to carry out operational actions. }\end{array}$ \\
\hline $\begin{array}{l}Y_{7} \text {, opportunity for learning and } \\
\text { sharing }\end{array}$ & $\begin{array}{l}\text { The extent to which an employee believes that the organization provides means for her/him to } \\
\text { learn \& share knowledge with others, which will enhance her/his capability to perform her/his } \\
\text { work. }\end{array}$ \\
\hline
\end{tabular}

Employee empowerment is defined in the framework as 'the extent to which employees feel they are given problemsolving and decision-making authority to take responsibility for using the organization's resources to achieve results.' This construct has four potential drivers as shown in Table 3.

Table 3. List of potential drivers of empowerment

(Permana et al., 2015)

\begin{tabular}{ll}
\hline Potential drivers & Definition \\
\hline $\begin{array}{l}Z_{1} \text {, superior's willingness to } \\
\text { delegate }\end{array}$ & $\begin{array}{l}\text { The extent to which an employee believes that her/his superior is inclined to entrust some of the } \\
\text { superior's decision-making authorities to her/him such that she/he can perform optimally without } \\
\text { having to wait for the superior's concurrence. }\end{array}$ \\
$\begin{array}{l}Z_{2}, \text { clear roles and } \\
\text { responsibility }\end{array}$ & $\begin{array}{l}\text { how clear are the roles and responsibilities to an employee with regards to her/his work, which help } \\
\text { her/him perform optimally. }\end{array}$ \\
$Z_{3}$, transformational & The extent to which an employee perceives how the state of intellectual stimulation, individualized \\
leadership & consideration, inspirational motivation, and individualized influence behaviour are displayed in the \\
& organization, especially by her/his leaders. \\
& $\begin{array}{l}\text { The degree to which an employee possesses the four positive-organizational-behaviour capacities of } \\
\text { self-efficacy (confidence), hope, optimism, and resiliency, which contribute to an optimistic explanatory } \\
\text { style through internalized perceptions of being in control. }\end{array}$ \\
\hline
\end{tabular}

Permana et al. (2015) argued in their propositions that the above drivers accounted for varying degrees of importance toward the constructs. In other words, they argued that certain engagement's drivers were more important than others in influencing employee engagement, certain enablement's drivers were more important than others in influencing employee enablement, and certain empowerment's drivers were more important than others in influencing employee empowerment. This paper presented the results of a study that assessed these propositions using analytic hierarchy process (AHP), and then further confirmed with a quadrant analysis of importance-vs-observance.

\subsection{Analytic hierarchy process}

The AHP was originally developed by Prof. Thomas Lorie Saaty (1977) of Wharton Business School and has been widely used as an effective tool for dealing with multi-drivers decision making, which helps decision makers to set priorities or importance. The AHP analysis simplifies importance ratings among the potential drivers by using a series of pairwise 
comparisons, and yet, it provides measures of judgment consistency, thus, reducing the bias in the ranking process.

The AHP can be used to measure and determine the ratio scale, either from discreet comparison or continuum. These comparisons can be taken from actual measurements or from scale-based questionnaires that reflect emotional feeling or relative preference. The AHP simplifies the rating process by grouping and arranging the pairs of the potential drivers in hierarchy levels and assigning numerical value on the importance of each potential driver. The foundation of the AHP is a set of axioms that delimit the scope of the problem environment (Saaty, 1986). This foundation consists of reciprocal comparison (i.e. the pairwise comparison matrix must have an opposite character, that is if $A$ is $k$ times more important than B, then B will be $1 / k$ less important than $A$ ), homogeneity (i.e. there must be likeness or similarity in the comparison), dependency (i.e. every level has a bond to be a complete hierarchy even when there is a possibility of an incomplete hierarchy), and expectation (i.e. the weight of a value is based on expectation or preference of the respondents).

Well-defined mathematical structure of consistent matrices is the base of the AHP. This structure has the ability to generate true or approximate weights (Merkin, 1979; Saaty 1980, 1994). It compares the potential drivers with respect to a criterion, in a natural, pairwise mode. Starting with defining the problem and determining the solution, it then develops a hierarchy structure of various criteria and alternative choices (in this study, these are the potential drivers) that will be ranked. The pairwise comparison matrix is structured such that it draws relative contribution or influence in each element against each criterion above it. The comparison is done based on choices or judgment from the respondents by assessing the various level of importance of a potential driver against the other in the pair. The AHP uses a fundamental scale of absolute numbers. Having been validated in decision problem experiments, this scale has also been proven in practice. With respect to quantitative and qualitative attributes, individual preferences are well captured with this scale sometimes even better than other scales (Saaty, 1980, 1994). The individual preferences are converted into ratio scale weights. This study used these weights to compare and rank the potential drivers.

The AHP is perhaps the most widely used decision making approach in the world today. Numerous actual applications, in which the AHP results were accepted and used, have confirmed its validity (Saaty, 1994). Evidences showed that the power and simplicity of AHP has led to a widespread acceptance and usage throughout the world. In addition to Expert Choice (the software that was used in this study), there have been several other successful commercial implementations of the AHP. The American Society for Testing and Materials (ASTM) has adopted the AHP as a standard practice for multiattribute decision analysis of investments related to buildings and building systems. The AHP process is taught in numerous universities and used extensively in organizations such as the Central Intelligence Agency that have carefully investigated AHP's theoretical underpinnings (Forman \& Gass, 2001).

\subsection{Quadrant analysis}

Upon obtaining the results from the AHP, this study continued with a quadrant analysis to confirm the AHP results. The quadrant analysis has its root back to Socrates questioning (or Socratic maieutics), which is a Socratic method of systematic questioning that renders problematic operational realities more user-friendly. This analysis concentrates the individual issues impacting a process or a system into an underlying source, and identifies straightforward solutions.

The modern day Quadrant Analysis, also known as Kano Analysis, was originally developed by Noriaki Kano in 1984 (Kano, Seraku, Takahashi, \& Tsuji, 1984). It was originally used for classifying customer needs and drivers of satisfaction. Kano model offers a better understanding of how customers evaluate a product, and assists companies to focus on the most important attributes to be improved (Gustafsson et al., 1999). In recent years, Kano model has been widely and successfully applied in strategic thinking, business planning and even product development to provide guidance with respect to innovation, competitiveness and product compliance (Watson, 2003). It is now employed in conjunction with market research surveys, customer surveys, and employee surveys to analyze gaps between expectations and actual performance. The results can help identifying areas for improvement. This study adopted Kano Analysis with quadrants of importance vs observance.

\section{Methodology}

\subsection{Sample}

Much of the literature on this topics focused on the senior level of leadership, which Senge (1996) categorized as executive leaders. However, high-performing systems differ from low-performing systems largely due to high-performing leaders at the shop floor level (Liker, 2004), whom Senge (1996) referred to as local line leaders. "Nothing can start 
without committed local line leaders ... they head organizational units that are large enough to be meaningful microcosms of the larger organization, and yet they have enough autonomy to be able to undertake meaningful change independent of the larger organization" (Senge, 1996). This justifies the relevance of choosing the foremen in people-intensive manufacturing organization as the main respondents in this study. Foremen are leaders at the shop floor level. They are the employee level that interacts intensively with the labor force, bridging management directives and production floor operational executions.

This study researched the drivers that brought about employee engagement, enablement, and empowerment; and thus, the research would bring about more meaning and impact to focus on people-intensive organizations. Manufacturing companies were chosen for this study due to their massive work force and the increasing importance of manufacturing industry. SCM World-Mesa International Survey (2014) revealed that, from its global survey of 158 companies worldwide, $83 \%$ of the respondents said that manufacturing industry is very important to their home country's economic competitiveness in the next five years. OECD Report (2012) showed that manufacturing industry contributed the largest share of foreign direct investment inflows into Indonesia. This study would therefore add values to the Indonesian business sector by focusing on manufacturing organizations.

The respondents for this study were drawn from eight manufacturing companies in Indonesia. Four companies are foreign direct investment multinational consumer goods companies, while the other four are local or national companies. These are companies in the business of fashion dolls, garments, electronics, packaging goods, and consumer goods. Employee populations range from a few hundred to several thousand people. Local or national companies were researched for their local practices that might contribute to the proposed framework. Multinational companies were chosen on the basis of their multi-national nature of operation to address multicultural issue in manufacturing environment.

The subject companies have foremen ranging from 12 people to 110 people. Totally, there were 257 foreman researched in this study, which represent $53 \%$ of the total foremen in the eight subject companies. In a period of about six months from mid-2014 until end of 2014, a total of 257 foremen were taken as the respondents of the pairwise comparisons of the subject matters used in the analytic hierarchy processes and the quadrant analysis of importance-vsobservance.

\subsection{Data collection}

Data collection for the relative-importance analysis was collected through pairwise survey questionnaire. Respondents were the foremen, gathered in a training room, guided one question by one question, to ensure understanding. They were asked to compare two potential drivers at a time, and to determine the extent of the comparison based on Saaty's scale (Saaty, 1990). There were $n^{\star}(n-1) / 2$ comparisons to make; thus, each respondent made a total of 82 comparisons (55 comparisons for variable Ex, 21 comparisons for variable $E_{Y}, 6$ comparisons for variable $E_{z}$ ) through the pairwise comparison survey as exemplified in Figure 1.

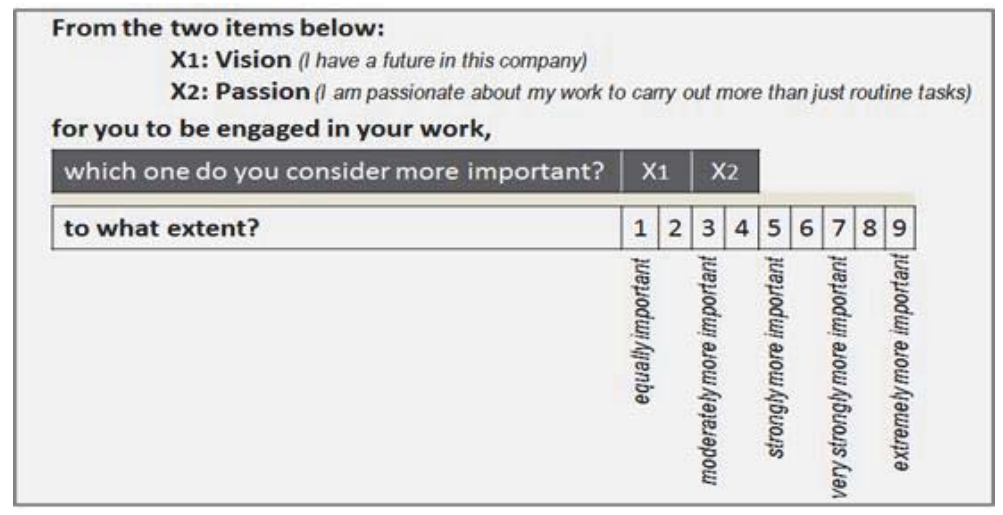

Figure 1. Example of AHP Pairwise Comparison Questionnaire

Workloads and business schedule did not allow for all respondents in a company to be out of their work areas at the same time; and thus, several batches of 15-20 people/batch needed to be conducted on different weeks. Re-examination 
sessions were also carried out to ensure that inconsistency was less than $10 \%$, as deemed acceptable (Saaty, 1990). The same respondents, on different dates, were also asked to rate each of the potential drivers on a five-point Likert scale based on what they observed (saw, heard, or experienced), through sets of questions, such as the following questions for potential drivers $\mathrm{X}_{1}$ (vision) and $\mathrm{X}_{2}$ (passion):

- (vision): How certain are you about your future in this company?

- (passion): How passionate are you toward your work to do more than just routine tasks?

This 'observance survey' was intended to find out what the respondents observed about each of the potential drivers in their daily work life.

\subsection{Data analysis}

This study is aimed at identifying the drivers which are the most important for predicting employees' engagement, enablement, and empowerment. The potential drivers as identified by Permana et al. (2015) as shown in Tables 1, 2, and 3 were ranked on relative-importance for further convergence. To analyze the relative-importance of the potential drivers, this study used the AHP. The pertinent data obtained from the pairwise comparisons were synthesized to obtain the weights of importance of the potential drivers of variables $E_{X}$ (Engagement), EY (Enablement), and $E_{z}$ (Empowerment). The results shown in this paper is an arithmetic average of the AHP results of 15 batches of pairwise questionnaire sessions of 15-20 respondents/batch.

The AHP analysis incorporates a technique for checking the consistency of the respondents' subjective assessment of pairwise comparisons. Saaty's rule of thumb is to accept only assessments with less than $10 \%$ inconsistency (Saaty, 1980). This study uses Expert Choice v.11 to synthesize the pairwise comparisons made by the respondents. For further details on how the AHP computes, such articles as "Using the Analytic Hierarchy Process for decision making in engineering applications: Some challenges" (Triantaphyllou and Mann, 1995) and "Decision making with the Analytic Hierarchy Process" (Saaty, 2008) are among excellent references.

The AHP analysis resulted in refinement of the list of potential drivers. Depending on the extent of their importance, the potential drivers were subject to elimination. Prior to finalization of the list, further confirmation was carried out using the observance survey. Adopting from the commonly known quadrant analysis or Kano analysis, the responses from the respondents were averaged, and then, cross-plotted against the relative-importance in an IOA (Importance-vsObservance Analysis) grid: relative-importance on $y$-axis and observance on $x$-axis. Since the relative-importance obtained from the AHP is a result of logarithmic average and the observance is a result of arithmetic average, the $y$-axis is logarithmic and $x$-axis is normal. The grid is then divided into four quadrants, to generate relative positions of the potential drivers: (1) high importance, low observance (categorized as 'underattended drivers') are potential drivers that have not obtained enough attention that is observable by the respondents, whereas these drivers are considered important, (2) high importance, high observance (categorized as 'obvious drivers') are potential drivers that are the strength and pillar of the related variable, (3) low importance, low observance (categorized as 'dubious drivers') are potential drivers that can be considered not important and not observable by the respondents, and pose no impact when eliminated from further study, and (4) low importance, high observance (categorized as 'overattended drivers') are potential drivers that are overly emphasized by the organization, whereas the respondents consider them as not important.

We argue that a potential driver is not instrumental to the model when and if it is not readily observed by the respondents in their working environment and is considered not important by them. In this context, dubious drivers are excluded from the final list. In a different context in the future which grants different circumstance, a dubious driver may become an important one.

\section{Results and Discussion}

The AHP results indicated that inconsistencies of less than 10\% were achieved in all potential drivers and on all respondents. This indicates that the qualitatively obtained (through pairwise comparisons) relative-importances of the potential drivers are quantitatively justifiable (by the acceptable level of consistency ratios as suggested by Saaty (1980)). Compiling the results from all pairwise questionnaire survey sessions, the relative-importances of potential drivers of engagement, enablement, and empowerment were found to be in the order and magnitude as shown in Figures 2, 3, and 4, respectively. These results were achieved with zero missing judgment and with $3.7 \%, 4.8 \%$, and $2.9 \%$ inconsistencies for engagement, enablement, and empowerment, respectively. Checking convergence, Eigenvalues were found to be in the average of $1.395 \times 10^{-12}, 1.417 \times 10^{-11}$, and $1.765 \times 10^{-9}$ for engagement, enablement, and empowerment, respectively. 


\begin{tabular}{|lr|}
\hline X1 (Vision) & $19.1 \%$ \\
X2 (Passion) & $17.4 \%$ \\
X8 (Trust in Leadership) & $14.5 \%$ \\
X9 (Psychological Capital) & $9.1 \%$ \\
X3 (Reward/Recognition) & $8.4 \%$ \\
X10 (Fit with Job) & $8.2 \%$ \\
X4 (Job Satisfaction) & $7.8 \%$ \\
X7 (Opportunity for Personal Growth) & $6.8 \%$ \\
X6 (Work Accomplishment) & $6.5 \%$ \\
X5 (Alignment of Value \& Interest) & $1.2 \%$ \\
X11 (Fit with Organization) & $1.0 \%$ \\
\hline
\end{tabular}

Figure 2. AHP Result for Relative Importance of Engagement's Potential Drivers

\begin{tabular}{|lrl|l|}
\hline Y4 (Supportive Working Environment) & $27.2 \%$ & \\
Y3 (Effective Work Processes) & $26.3 \%$ & \\
Y7 (Opportunity for Learning) & $12.9 \%$ & \\
Y1 (Work Equipment \& Supplies) & $11.8 \%$ & \\
Y2 (Clear Direction) & $10.8 \%$ & \\
Y6 (Data Sharing) & $8.8 \%$ & \\
Y5 (Job Design) & $2.2 \%$ & \\
\hline
\end{tabular}

Figure 3. AHP Result for Relative Importance of Enablement's Potential Drivers

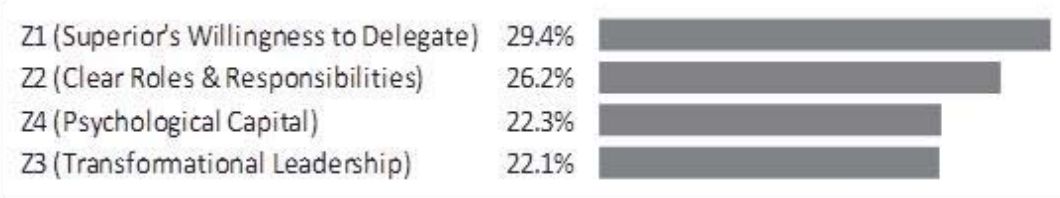

Figure 4. AHP Result for Relative Importance of Empowerment's Potential Drivers

As mentioned earlier, observance survey was conducted to find out what the respondents observed on each of the potential drivers in their daily work life. This was done as a further confirmation of each driver. The results of the survey were plotted against the relative-importance in an Importance-Observance Analysis (IOA) grid. Figures 5, 6, and 7 show the IOA results for each of the potential drivers.

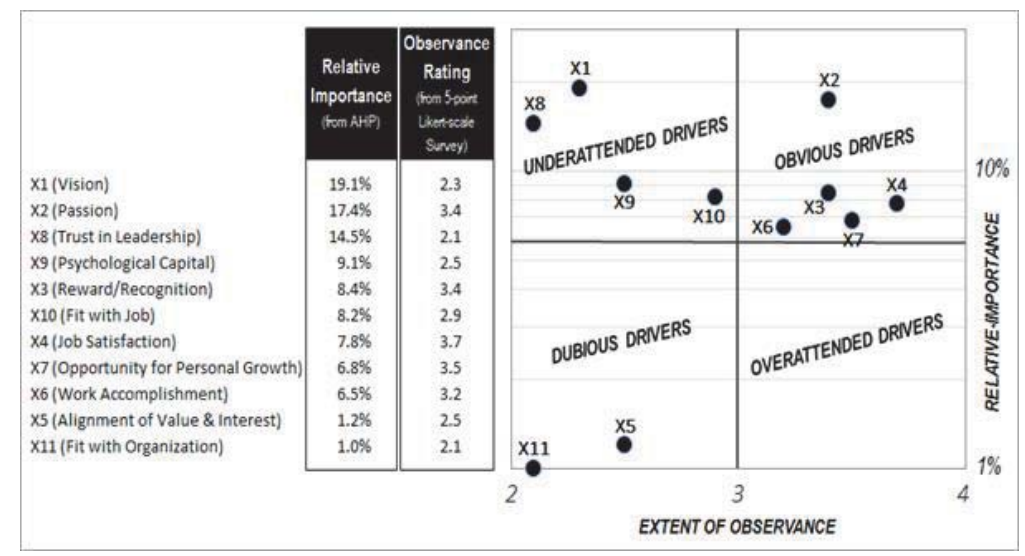

Figure 5. Importance-Observance Analysis for Potential Drivers of Engagement 


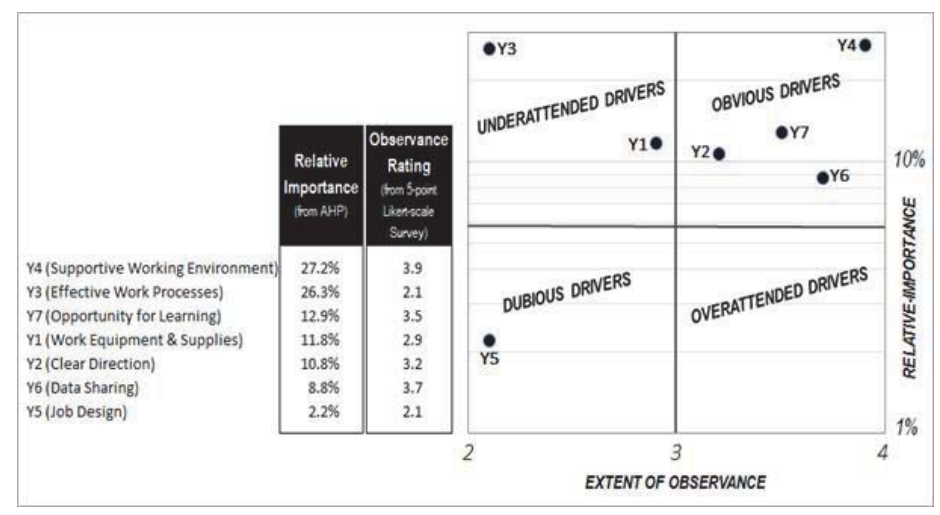

Figure 6. Importance-Observance Analysis for Potential Drivers of Enablement

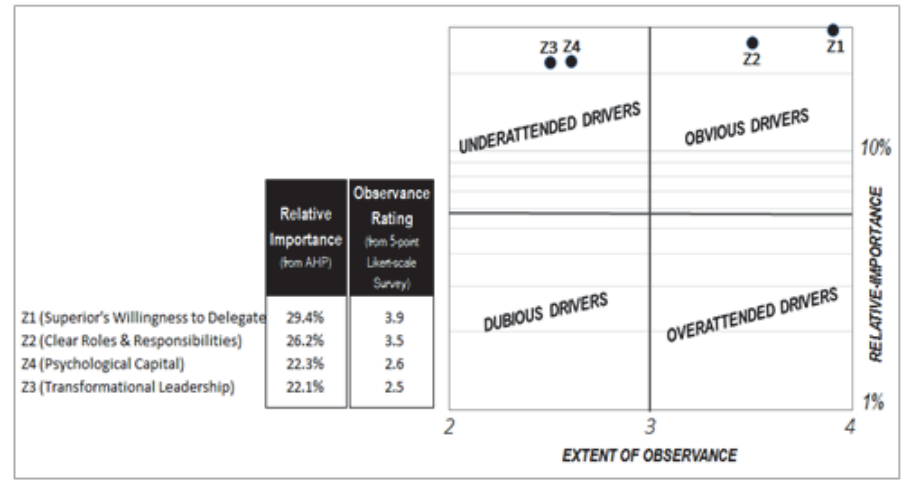

Figure 7. Importance-Observance Analysis for Potential Drivers of Empowerment

The AHP analysis result showed that there are potential drivers that are highly important; and there are potential drivers whose importances are to the very small extent. "Being confident that she/he has a future in the organization" appeared to be the most important driver of engagement according to the respondents. This indicated that the respondents suggested they became engaged when and if they felt a vested interest in the company's success, as noted by Wilson (2007). "Supportive working environment" turned out to be the most important driver for enabling employees. The respondents felt that being in a "suitable habitat" was of utmost importance for them to be able to perform excellently. Other drivers would not function well when and if the "habitat" worked against them. Towers-Watson (2011) argued that to perform at their best, employees needed healthful environments that helped sustain high energy levels. "Superior's willingness to delegate" was considered by the respondents to be the most important driver for empowering them, albeit all the four drivers were considered relatively with similar importance. Spreitzer (1995) argued that empowerment went beyond enablement which focused mainly on providing employees with the tools to do the job but not necessarily giving them the authority to do it. Thus, giving authority (i.e. willingness to delegate) was weighed as of utmost importance to the respondents to be empowered.

On the least side of relative-importance, the study unveiled that the respondents considered "alignment of values and interest" and "fit with organization" to be least important for them to be engaged. The IOA indicated that these potential drivers were not much observed by the respondents in their daily work life. Finding on the most-important driver (i.e. vision) suggested that their consideration on what was important for engaging them related to their "basic need" of vested interest in company's success (Wilson, 2007). With this level of "need", their rating on the relative importance thus did not place much weight on the "alignment of value and interest" and "fit with organization", which lay higher than "basic need' in Maslow's (1943) hierarchy of needs. In other words, these drivers were not of much concern to them, and thus, not suitable items to be surveyed to the foremen level. This was also true for "job design", which they deemed as least important for enabling them, and it was not much of something that was observable in their daily work life. Job design (Wright, 2008) is about having people with the right skills for the job. This finding, along with what was described above, suggested that the respondents regarded themselves as enabled largely because they worked in a "suitable habitat" of 
teams and collaboration, not very much due to "having the right skills". These three potential drivers evidently fell into the quadrant of dubious drivers in the eyes of the respondents, and thus, were considered to be excluded.

Despite the high rating of relative-importance, the respondents rated "vision" (i.e. confident that she/he has a future in the company) very low on the extent to which they observed this driver into effect in their daily work life. Similarly, the respondents also rated "psychological capital" and "transformational leadership" very low on the extent to which they observed these drivers into effect in their daily work life, although they considered these drivers as highly important. In other words, they considered these highly important drivers of engagement and empowerment, respectively, to be underattended by the organization. These are where the organization needs to focus on if it aims at engaging and empowering its employees. On the enablement side, the respondents rated "supportive working environment" very high on the extent to which they observed this driver into effect in their daily work life. Clearly, they regarded supportive working environment as an obvious driver of enablement. As for empowerment, they rated "superior's willingness to delegate" and "clear roles and responsibilities" very high on the extent to which they observed these drivers into effect in their daily work life. In other words, they recognized these drivers as obvious drivers of empowerment.

\section{Conclusion}

This study has identified important drivers to be included in the models of employee engagement, enablement, and empowerment, among a set of potential drivers identified through the literature research. Among the drivers included in the models, the results have also shown which drivers are the most important for predicting employee engagement, enablement, and empowerment. The research objective has been met as the results have unveiled the fact that there is a key driver that is the most important for predicting employee engagement, a key driver for enablement, and a key driver for empowerment. The study also revealed potential drivers that evidently fell into the quadrant of dubious drivers in the eyes of the respondents, and thus, were considered to be excluded (as shown in parenthesis in Figure 8) for being not instrumental to the model. Thus, the framework as proposed by Permana et al. (2015) is revised as shown in Figure 8, with the drivers listed in the order of their importance as ranked by the respondents through the pairwise comparisons.

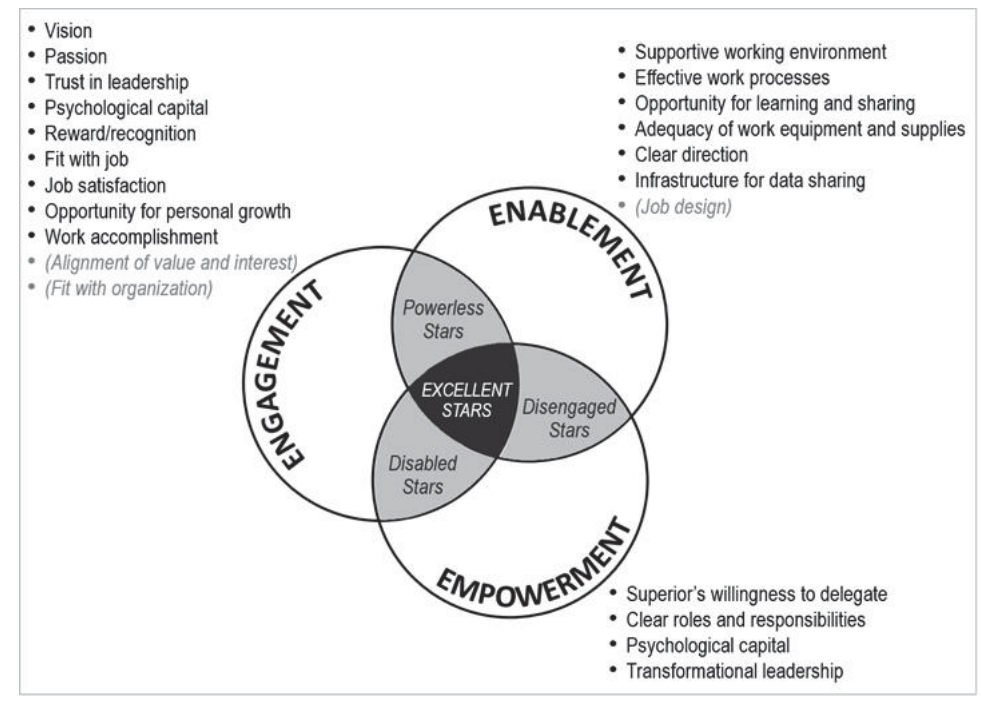

Figure 8. The Revised Framework

The theory development of the proposed framework is a key contribution of this research. It is expected to provide a new approach in understanding the antecedents of employee engagement, enablement, and empowerment. The results can provide management an empirical basis for making decisions and taking action on the most important factors for influencing employee engagement, enablement, and empowerment, which in turn can shed light on the understanding of how to pave the way for developing employees. Furthermore, knowing the drivers will help organizations to formulate what needs to be done to engage, to enable, and to empower employees. By understanding what drive their engagement, enablement, and empowerment, businesses can apply the knowledge to help nurturing their employees, which in turn, will bring about business excellence of the organizations. 


\section{Future Research}

This study provided a new approach in understanding how to engage, enable, and empower employee, especially the foremen level in manufacturing organizations, in order to develop their excellence. Having explored key drivers of each construct, this study however has not addressed the question of whether or not there are links between them and the question of how employee excellence correlates with employee engagement, enablement, and empowerment. The understanding of this framework will even be much better when all the three constructs are further examined for answers to the above questions. Future research should therefore be directed around the questions of whether engagement, enablement, and empowerment are mutually exclusive of each other when influencing employee excellence. It can also be aimed at examining how engagement, enablement, and empowerment jointly influence employee excellence. Future research may also include exploration on how to grow the drivers in order to further the development of employee excellence.

Manufacturing organizations, with their foremen level, were the focus of this study. With this focus, further use of the results of the study should be applied with care, for they may not be generalizable to other types of organizations or other sections of organizations, and may give different results when applied to different level of employees. This "gap" may suggest topics for future research to deep dive the extent of the applicability of the framework. Therefore, a recommendation for future research to fill in the gap would be to reproduce this study in different type of organizations or industries, or even countries, to investigate the influence of cross-border cultural differences. Another consideration for additional studies would be to examine the findings with different groups of employees. These additional future researches can be expected to provide a much better roadmap to building employee excellence, which in turn, can help organizations to excel.

\section{References}

Conger, J. \& Kanungo, R. (1988). The empowerment process: Integrating theory and practice. Academy of Management Review, 13, 471-482.

Forman, E.H., \& Gass, S.I. (2001). The Analytic Hierarchy Process - An Exposition. Operations Research, 49(4), 469-486.

Gustafsson, A., Ekdahl, F., \& Edvardsson, B. (1999). Customer focused service development in practice: a case study at Scandinavian Airlines System (SAS). International Journal of Service Management, 10(4), 344-358.

Hay Group Report (2010). Hay Study Report 2010 on Employee Opinion Survey.

Kano, N., Seraku, N., Takahashi, F, \& Tsuji, S. (1984). Attractive quality and must-be quality. The Journal of the Japanese Society for Quality Control, 14(2), 39-48.

Liker, J.K. (2004). The Toyota Way. New York: McGraw-Hill.

Liker, J.K. \& Meier, D.P. (2007). The Toyota Talent: Developing Your People the Toyota Way. New York: McGraw-Hill.

Maslow, A.H. (1943). A theory of human motivation. Psychological Review, 50(4), 370-396. Retrieved January 2015, from http://psychclassics.yorku.ca/Maslow/motivation.htm

Merkin, B.G. (1979). Group Choice. New York: John Wiley \& Sons.

OECD Report. (2012). OECD Economic Surveys: Indonesia 2012. OECD Publishing. doi: 10.1787/eco_surveys-idn-2012-en

Permana, I., Tjakraatmadja, J.H., Larso, D., \& Wicaksono, A. (2015). Exploring potential drivers of employee engagement, enablement, and empowerment: A quest toward developing a framework for building sustainable employee excellence for manufacturing environment in Indonesia. Mediterranean Journal of Social Sciences, 6(2), 577-587. Doi:10.5901/mjss.2015.v6n2s1p577

Saaty, T.L (1977). A scaling method for priorities in hierarchical structures". Journal of Mathematical Psychology, 15, 57-68.

Saaty, T.L. (1980). The Analytic Hierarchy Process. New York: McGraw-Hill.

Saaty, T.L. (1986). Axiomatic foundation of the analytic hierarchy process. Management Science, 32, 841-855.

Saaty, T.L. (1990). How to make a decision: The Analytic Hierarchy Process. European Journal of Operational Research, 48, 9-26.

Saaty, T.L. (1994). Fundamentals of Decision Making and Priority Theory with the Analytic Hierarchy Process. Pittsburgh: RWS Publications.

Saaty, T.L. (2008). Decision making with the analytic hierarchy process. International Journal of Services Sciences, 1(1), 83-98.

SCM Word-Mesa International Survey. (2014). The Future of Manufacturing. Recorded webinar.

Senge, P.M. (1996). Leading learning organizations: The bold, the powerful, and the invisible. A shortened version of P. Senge, Leading Learning Organizations (MIT Center for Organizational Learning Research Monograph), Cambridge, Mass.: MIT Center for Organizational Learning.

Triantaphyllou, E., \& Mann, S.H. (1995). Using the analytic hierarchy process for decision making in engineering applications: Some challenges. International Journal of Industrial Engineering: Applications and Practice, 2(1), 35-44.

Watson, G. (2003). Customer focus and competitiveness. In Six Sigma and Related Studies in the Quality Disciplines, edited by Kenneth S. Stephens. Milwaukee: ASQ Quality Press. 